\title{
A Single Institution's Experience of Definitive Radiotherapy Using Volumetric-modulated Arc Therapy for Hypopharyngeal Cancers
}

\author{
KATSUMARO KUBO ${ }^{1}$, YUJI MURAKAMI ${ }^{1}$, NOBUKI IMANO ${ }^{1}$, YUKI TAKEUCHI ${ }^{1}$, \\ IKUNO NISHIBUCHI ${ }^{1}$, TOMOKI KIMURA ${ }^{1}$, DAISUKE KAWAHARA ${ }^{1}$, KENTARO MIKI ${ }^{1}$, \\ AKITO SAITO $^{1}$, TAKEO NAKASHIMA ${ }^{1}$, TAKAO HAMAMOTO ${ }^{2}$, \\ TSUTOMU UEDA ${ }^{2}$, SACHIO TAKENO ${ }^{2}$ and YASUSHI NAGATA ${ }^{1}$ \\ ${ }^{1}$ Department of Radiation Oncology, Hiroshima University Hospital, Hiroshima, Japan; \\ ${ }^{2}$ Department of Otorhinolaryngology, Hiroshima University Hospital, Hiroshima, Japan
}

\begin{abstract}
Background/Aim: The present study aimed to analyze the treatment outcome after definitive radiotherapy $(d R T)$ using volumetric-modulated arc therapy (VMAT) in patients with hypopharyngeal cancer (HPC), including an examination of late toxicities. Patients and Methods: A total of 62 patients with HPC, who underwent dRT using VMAT, were analyzed. Overall survival (OS), progression-free survival (PFS), laryngoesophageal dysfunction-free survival (LEDFS), and locoregional control (LRC) were calculated. Results: The median follow-up period was 49 months. The 3- and 5-year OS, PFS, LEDFS, and LRC rates were $77 \%$ and $60 \%, 61 \%$ and $56 \%, 66 \%$ and $53 \%$, and both $79 \%$, respectively. Regarding late toxicities, 11 (17.7\%) patients developed grade $\geq 2$ late toxicity. Grade 3 dysphagia was observed in $4(6.5 \%)$ patients, and grade 2 xerostomia in 6 (9.7\%). Conclusion: VMAT was an effective treatment for $H P C$, with a low incidence of late toxicities.
\end{abstract}

Hypopharyngeal cancer (HPC) is a relatively uncommon malignancy, and the management of this disease varies by Institution (1). Radiotherapy (RT) is a well-established standard treatment for head and neck squamous cell carcinoma, and also one of the treatment options for $\operatorname{HPC}(2,3)$. Definitive RT with or without chemotherapy is considered an organ preservation

This article is freely accessible online.

Correspondence to: Katsumaro Kubo, Department of Radiation Oncology, Hiroshima University Hospital 1-2-3 Kasumi Minamiku Hiroshima-shi, Hiroshima 734-8553, Japan. Tel: +81 822575555 , Fax: +81 822571546, e-mail: maro1987@hotmail.co.jp

Key Words: Hypopharyngeal cancer, volumetric-modulated arc therapy, laryngoesophageal dysfunction-free survival. approach. However, recently, late toxicities after definitive RT, especially chemoradiotherapy (CRT), have gathered attention. The long-term results of the Radiation Therapy Oncology Group (RTOG) 91-11 trial concluded that new strategies which improve organ preservation and function with less morbidity were needed (4).

We believe that a new radiation technique, such as intensitymodulated radiotherapy (IMRT), is one method of addressing the recommendations of the RTOG 91-11. IMRT, a highprecision radiotherapy, causes fewer adverse events in patients with head and neck cancer while providing similar local control in comparison to three-dimensional conformal radiotherapy (3D-CRT) (5). Volumetric-modulated arc therapy (VMAT) is a further technique that evolved from IMRT. VMAT is able to deliver highly conformal treatment, sparing nearby organs at risk. These advances in radiation techniques might contribute to the reduction of late toxicities after definitive RT and improve organ preservation. However, the clinical findings of IMRT for patients with HPC are more limited than those for nasopharyngeal cancer or oropharyngeal cancer (OPC), and the clinical outcome after definitive RT using current radiation techniques such as IMRT for HPC is unclear $(6,7)$.

Therefore, in the present study, we analyzed treatment outcomes after definitive RT using VMAT in patients with HPC, including examination of late toxicities such as laryngeal and pharyngeal dysfunction.

\section{Patients and Methods}

Patients. Data from patients, who were diagnosed with HPC and underwent definitive RT at the Hiroshima University Hospital (Hiroshima, Japan) between July, 2009 and December, 2017, were retrospectively analyzed. Individuals who fulfilled the following criteria were included in the present study: histological diagnosis of squamous cell carcinoma of the hypopharynx; no distant metastasis; and definitive RT treatment using VMAT. A multidisciplinary head 
and neck cancer team of the Cancer Board discussed the treatment of each HPC patient.

Before definitive RT, all patients underwent clinical evaluation including assessment of medical history, physical examinations and laboratory investigations, endoscopy, ultrasound examination, and radiographic studies. Laboratory investigations included complete blood cell count, liver function, renal function, and measurement of electrolyte levels. Radiographic studies included contrast-enhanced computed tomography (CT), ${ }^{18} \mathrm{~F}$-fluorodeoxyglucose positron emission tomography-CT (PET/CT), and magnetic resonance imaging (MRI). The clinical tumor node metastasis (TNM) stage was defined according to the Tumor Node Metastasis classification (Union for International Cancer Control, 7th Edition). The study was approved by the Human Ethics Review Committee of Hiroshima University Hospital. The need for informed consent was waived due to the retrospective nature of this study.

\section{Treatment}

Radiotherapy. Before treatment, the heads of all patients were noninvasively immobilized using a thermoplastic head-neck-shoulder mask, and subjected to contrast-enhanced CT. CT images were acquired at a slice thickness of $2.5 \mathrm{~mm}$ and imported to the Eclipse treatment planning system (Varian Medical Systems, Palo Alto, CA, USA) for VMAT planning (Rapidarc; Varian Medical Systems). Gross tumor volume (GTV) was based on clinical, endoscopic, and radiological findings according to $\mathrm{CT}$, MRI, and PET/CT. Clinical target volume (CTV) 70 was generated by adding a $5-10 \mathrm{~mm}$ margin from the GTV, including the primary tumor and affected lymph nodes. CTV63 included the high-risk areas and was created individually based on primary tumor site and lymph node metastases. CTV56 included elective nodal regions. Planning target volume (PTV) 70, PTV63, and PTV56 were generated by adding a 5-10 mm margin from CTV70, CTV63, and CTV56. Usually, 2 or 3 axial coplanar arcs were used for VMAT. All treatment plans were designed based on a TrueBeam linear accelerator equipped with 5 mm leaf-width multi-leaf collimators (Varian Medical Systems). All plans were normalized so that PTV70 D95 (the dose that covers 95\% of the PTV70) was equal to 70 Gy using 6-10 MV photon beams. PTV70, PTV63, and PTV56 received a total dose of $70 \mathrm{~Gy}$, $63 \mathrm{~Gy}$, and 56 Gy in 35 fractions, respectively. Cone-beam CT was performed daily for patient set-up and positioning verification.

Chemotherapy. The concurrent chemotherapy regimen was 3 cycles of cisplatin $100 \mathrm{mg} / \mathrm{m}^{2}$ at an interval of 3 weeks. Before 2012, the concurrent chemotherapy regimen was 2 cycles of cisplatin plus 5fluorouracil. If the administration of cisplatin was not appropriate due to the patient's general condition, renal function, age, carboplatin or cetuximub was administered.

Regarding patients with Stage IV disease, induction chemotherapy was indicated. The medication administered was combination chemotherapy consisting of docetaxel $\left(70 \mathrm{mg} / \mathrm{m}^{2}\right)$ on day 1 , cisplatin $\left(70 \mathrm{mg} / \mathrm{m}^{2}\right)$ on day 4 , and 5-fluorouracil $(750$ $\mathrm{mg} / \mathrm{m}^{2}$ ) by $24 \mathrm{~h}$ continuous infusion for 5 days (i.e., TPF therapy). Two cycles at 3- or 4-week intervals were planned.

Statistical analysis. The Kaplan-Meier method was used to calculate overall survival (OS), progression-free survival (PFS), laryngoesophageal dysfunction-free survival (LEDFS), and locoregional control (LRC). OS was defined as the date of initiation of RT to the date of the final follow-up or death from any cause. PFS was defined as the date of initiation of RT to the date of any tumor progression or death from any cause. LEDFS was analyzed to evaluate organ preservation in the cohort. For LEDFS, the Larynx Preservation Consensus Panel recommends including death, local recurrence, total or partial laryngectomy, tracheotomy at $\geq 2$ years, or use of a feeding tube at $\geq 2$ years (8). Swallowing function was evaluated with videofluorography. LRC was estimated as the RT start date until the date of any locoregional progression; patients without locoregional progression at the time of death were censored. Univariate analyses using the Cochran-Mantel-Haenszel test and multivariate analyses using the Cox proportional hazards model were performed to compare and determine statistical differences in OS and LEDFS. BellCurve version 3.20 (Social Survey Research Information Co., Ltd., Tokyo, Japan) for Excel (Microsoft Corporation, Redmond, WA, USA) was used to perform statistical analyses. Differences with $p$-values $<0.05$ were considered statistically significant. Treatmentrelated toxicities were evaluated according to the Common Terminology Criteria for Adverse Events version 4.0.

\section{Results}

Patients. A total of 62 eligible patients, the characteristics of whom are summarized in Table I, were enrolled in the present study. The median age of the patients was 66 years (range $=37-85$ years) and $91.9 \%$ were men. The most common primary tumor site was pyriform sinus $(62.9 \%)$, followed by posterior pharyngeal wall $(29.0 \%)$, and postcricoid area $(8.1 \%) . \mathrm{T} 1, \mathrm{~T} 2, \mathrm{~T} 3, \mathrm{~T} 4 \mathrm{a}$, and $\mathrm{T} 4 \mathrm{~b}$ disease were observed in 5 $(8.1 \%), 19(30.6 \%), 8(12.9 \%), 18(29.0 \%)$, and $12(19.4 \%)$ patients, respectively. Regarding lymph node metastases, N0, $\mathrm{N} 1, \mathrm{~N} 2$, and $\mathrm{N} 3$ disease were observed in 22 (35.5\%), 3 $(4.8 \%), 35(56.5 \%)$, and $2(3.2 \%)$ patients, respectively. Stage I, Stage II, Stage III, Stage IVA, and Stage IVB disease were observed in 5 (8.1\%), 7 (11.3\%), 3 (4.8\%), 33 (53.2\%), and $14(22.6 \%)$ patients, respectively. Induction chemotherapy was conducted in $39(62.9 \%)$ patients. Fifty-six (90.3\%) patients received chemotherapy concurrently with RT. Cisplatin was administered to $45(72.6 \%)$ patients, cisplatin plus 5-fluorouracil to $7(11.3 \%)$, carboplatin to $1(1.6 \%)$, carboplatin plus 5-fluorouracil to $1(1.6 \%)$, and cetuximub to $2(3.2 \%)$ with RT. Of 6 patients receiving RT alone, 5 had Stage I disease and 1 had Stage II disease. Median follow-up at the time of evaluation was 49 months (range=26-114 months) in survivors.

Treatment outcome. Locoregional control and recurrence patterns. The 3- and 5-year LRC rates were both 78.7\% [95\% confidence interval $(\mathrm{CI})=68.4-89.0 \%$ ]. Disease progression was observed in $21(33.9 \%)$ patients. Regarding the pattern of initial recurrence, $11(17.7 \%)$ patients experienced locoregional recurrence, $8(12.9 \%)$ developed distant metastases, and $2(3.2 \%)$ experienced both locoregional and distant failure. Overall, during the observation period, 13 (21.0\%) patients experienced locoregional recurrence, and 15 (24.2\%) developed distant metastases. 
Table I. Patient characteristics.

\begin{tabular}{|c|c|c|}
\hline & $\mathrm{N}=62$ & $100(\%)$ \\
\hline Age, years, median (range) & $66(37-85)$ & - \\
\hline \multicolumn{3}{|l|}{ Gender } \\
\hline Male & 57 & 91.9 \\
\hline Female & 5 & 8.1 \\
\hline \multicolumn{3}{|l|}{ Location } \\
\hline Postcricoid area & 5 & 8.1 \\
\hline Pyriform sinus & 39 & 62.9 \\
\hline Posterior pharyngeal wall & 18 & 29.0 \\
\hline \multicolumn{3}{|l|}{$\mathrm{T}$ category } \\
\hline $\mathrm{T} 1$ & 5 & 8.1 \\
\hline $\mathrm{T} 2$ & 19 & 30.6 \\
\hline $\mathrm{T} 3$ & 8 & 12.9 \\
\hline $\mathrm{T} 4 \mathrm{a}$ & 18 & 29.0 \\
\hline $\mathrm{T} 4 \mathrm{~b}$ & 12 & 19.4 \\
\hline \multicolumn{3}{|l|}{$\mathrm{N}$ category } \\
\hline NO & 22 & 35.5 \\
\hline N1 & 3 & 4.8 \\
\hline $\mathrm{N} 2 \mathrm{a}$ & 0 & 0.0 \\
\hline $\mathrm{N} 2 \mathrm{~b}$ & 28 & 45.2 \\
\hline $\mathrm{N} 2 \mathrm{c}$ & 7 & 11.3 \\
\hline N3 & 2 & 3.2 \\
\hline \multicolumn{3}{|l|}{ Clinical stage } \\
\hline I & 5 & 8.1 \\
\hline II & 7 & 11.3 \\
\hline III & 3 & 4.8 \\
\hline IVA & 33 & 53.2 \\
\hline IVB & 14 & 22.6 \\
\hline PET-CT & Yes & 5690.3 \\
\hline Induction chemotherapy & Yes & 3962.9 \\
\hline Concurrent chemotherapy & 56 & 90.3 \\
\hline Ciplatin & 45 & 72.6 \\
\hline Cisplatin + 5-fluorouracil & 7 & 11.3 \\
\hline Carboplatin & 1 & 1.6 \\
\hline Carboplatin +5 -fluorouracil & 1 & 1.6 \\
\hline Cetuximub & 2 & 3.2 \\
\hline Smoking history & Yes & 5080.6 \\
\hline
\end{tabular}

PET-CT: ${ }^{18} \mathrm{~F}$-fluorodeoxyglucose positron emission tomography computed tomography.

Regarding salvage treatment, of the 13 patients with locoregional recurrence, 10 patients underwent salvage surgery, including neck dissection in 6 patients, total laryngopharyngoesophagectomy in 2 , partial pharyngectomy in 1 , and endoscopic submucosal dissection in 1 .

Survival. OS, PFS, and LEDFS rates in all patients are presented in Figure 1. At the last follow-up, 39 (62.9\%) patients were still alive, $16(25.8 \%)$ died from the disease, and 7 (11.3\%) died of other causes. Of the 39 survivors, 36 were alive without disease, and 3 had recurrence of HPC. Of the 7 patients who died of other causes, 3 died from other cancers, 2 died from pneumonia, 1 died from pneumonitis, and 1 died from ischemic heart disease. Of the 2 patients who died of pneumonia, both patients did not have radiation-related severe dysphagia, and the association between the cause of death and RT was unclear. The 3- and 5-year OS rates were 76.7\% (95\% $\mathrm{CI}=65.9-87.4 \%)$ and $60.2 \%(95 \% \mathrm{CI}=46.4-74.0 \%)$, respectively. The 3- and 5-year PFS rates were 60.9\% (95\% CI=48.6-73.1\%) and $55.6 \%(95 \% \mathrm{CI}=42.4-68.8 \%)$, respectively.

The 3- and 5-year LEDFS rates were $65.5 \%$ (95\% CI=53.5$77.5 \%)$ and $52.8 \%(95 \% \mathrm{CI}=38.8-66.8 \%)$, respectively. Events associated with laryngoesophageal dysfunction included death in $13(21.0 \%)$ patients ( 7 died from the disease, and 6 died of other causes), local recurrence in $8(12.9 \%)$, tracheotomy in 2 (3.2\%), and feeding tube at $\geq 2$ years in $5(8.1 \%)$. Of the 5 patients who depended on a feeding tube, 1 required a feeding tube due to hypoxic-ischemic encephalopathy after food asphyxiation, although the patient did not have severe dysphagia. Another patient could not eat before treatment because of the tumor spread, and needed a feeding tube until the end of the observation period. The other 3 patients required a feeding tube due to RT-related dysphagia.

Toxicity. Acute and late toxicities are listed in Table II. Overall, grade $\geq 3$ acute toxicities were observed in 47 (75.8\%) patients. During RT, grade 3-4 hematological toxicities included: leukopenia in $23(37.1 \%)$ patients, neutropenia in 19 $(30.6 \%)$, and anemia in $6(9.7 \%)$. The most common grade 3 non-hematological toxicity was mucositis $(46.8 \%)$, followed by dysphagia (40.3\%), and dermatitis (30.6\%). Regarding late toxicities, $11(17.7 \%)$ patients developed grade $\geq 2$ late toxicity, and grade 2 xerostomia was observed in $6(9.7 \%)$. Grade 3 dysphagia was observed in $4(6.5 \%)$ patients. There were no grade 4-5 late toxicities in the cohort.

Predictive factors of overall survival and laryngoesophageal dysfunction-free survival. The results of univariate and multivariate analyses of OS and LEDFS are summarized in Table III. In multivariate analysis, N category (N0 vs. N1-3) was a significant predictive factor of OS. Location (pyriform sinus vs. others) and N category (N0 vs. N1-3) were significant predictive factors of LEDFS. The LEDFS rates according to location and $\mathrm{N}$ category are presented in Figure 2.

\section{Discussion}

Through the advancement of radiation techniques, definitive RT has become a mainstream treatment for HPC. Early-stage disease can be treated equally effectively with surgery or RT, and definitive RT also has a role in the curative management of locally advanced cancers $(2,3)$. However, while definitive RT with or without chemotherapy is regarded as an organ preservation approach, late toxicities such as laryngeal and pharyngeal dysfunction are problematic. A previous study reported that almost $40 \%$ of patients with locally advanced head and neck cancer treated with definitive RT experienced longterm dysphagia (9). In addition, it was reported that $10-20 \%$ of 
a

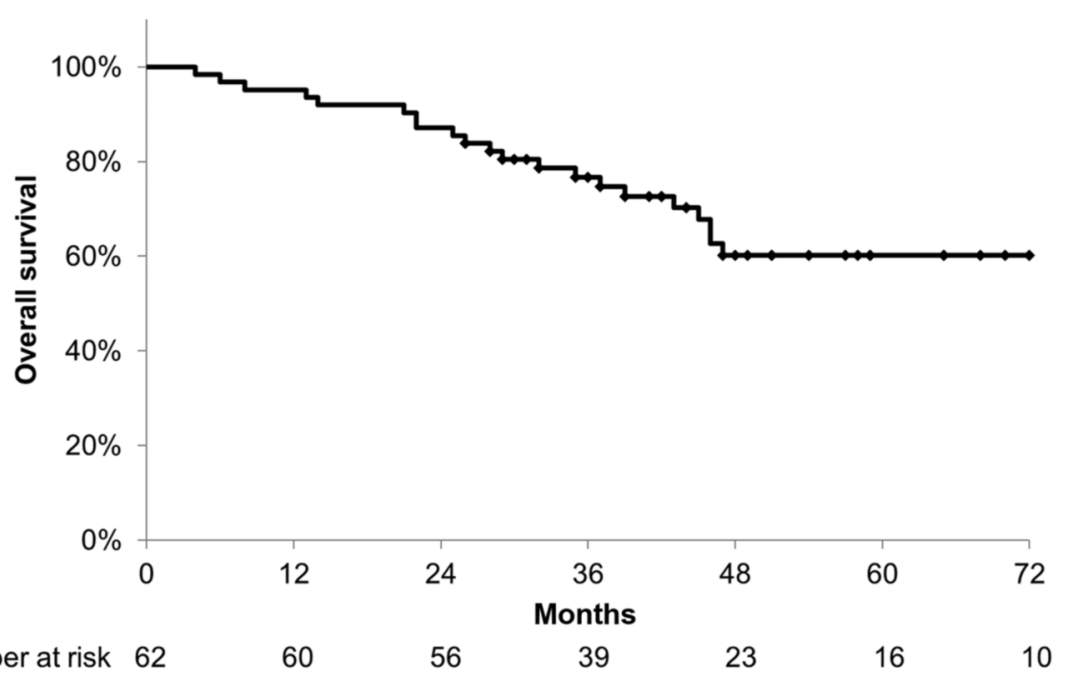

Number at risk 62

39

23

10

b

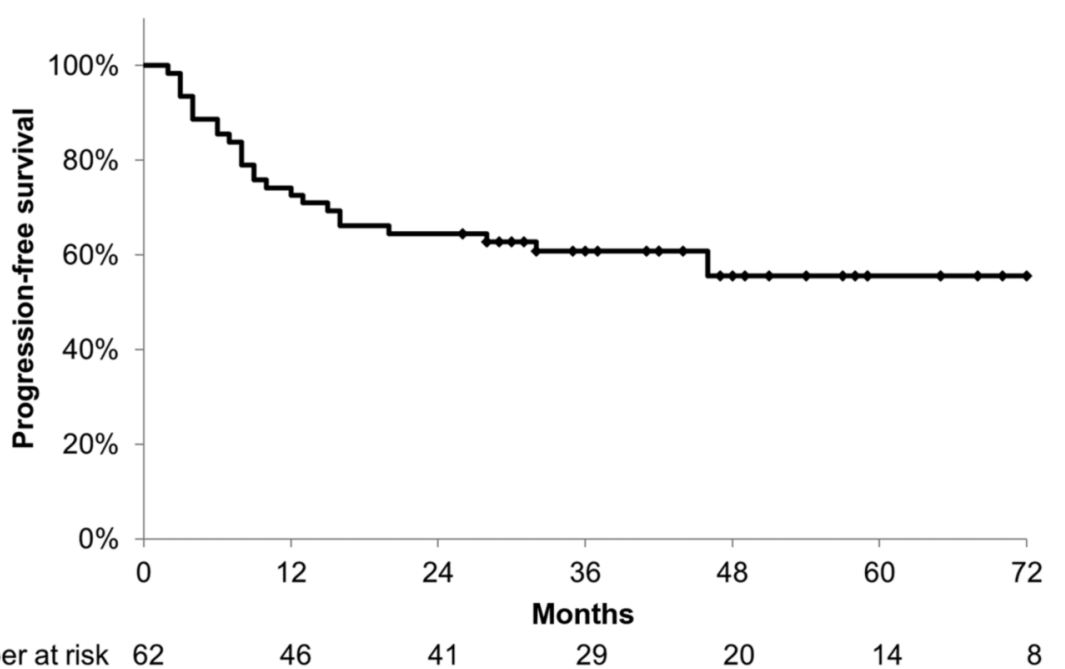

Number at risk 62

46

41

29

20 8

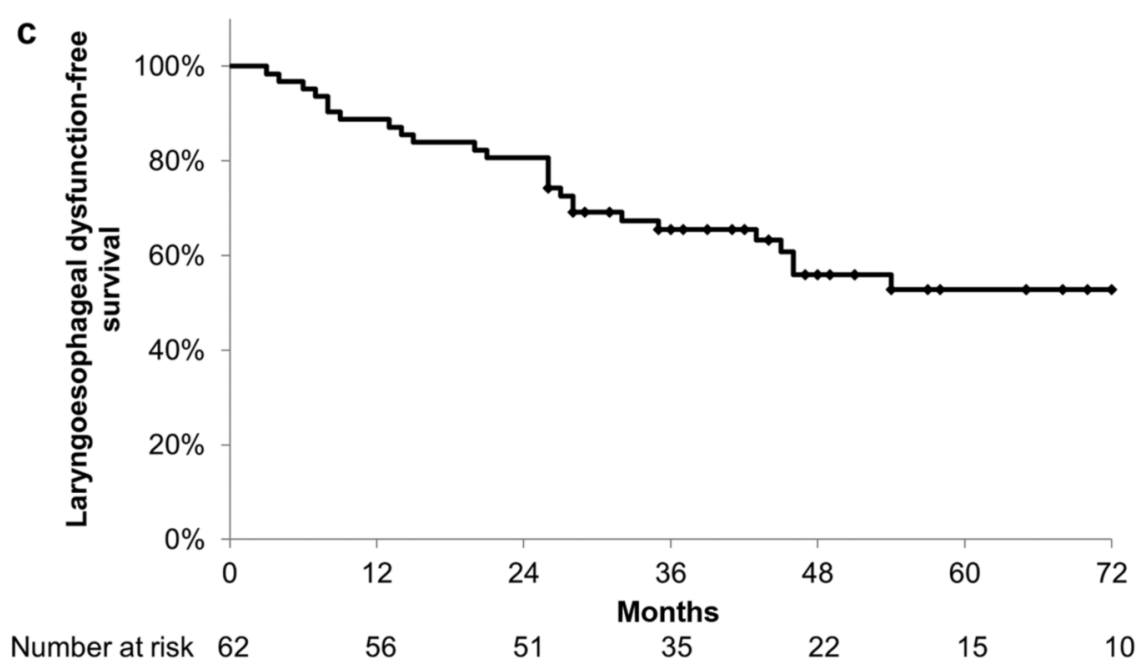

Figure 1. Overall survival (OS), progression-free survival (PFS), and laryngoesophageal dysfunction-free survival (LEDFS) in all patients. (a) The 3-and 5-year OS rates were $76.7 \%$ and $60.2 \%$, respectively. (b) The 3- and 5-year PFS rates were 60.9\% and 55.6\%, respectively. (c) The 3-and 5 -year LEDFS rates were $65.6 \%$ and $52.8 \%$, respectively. 

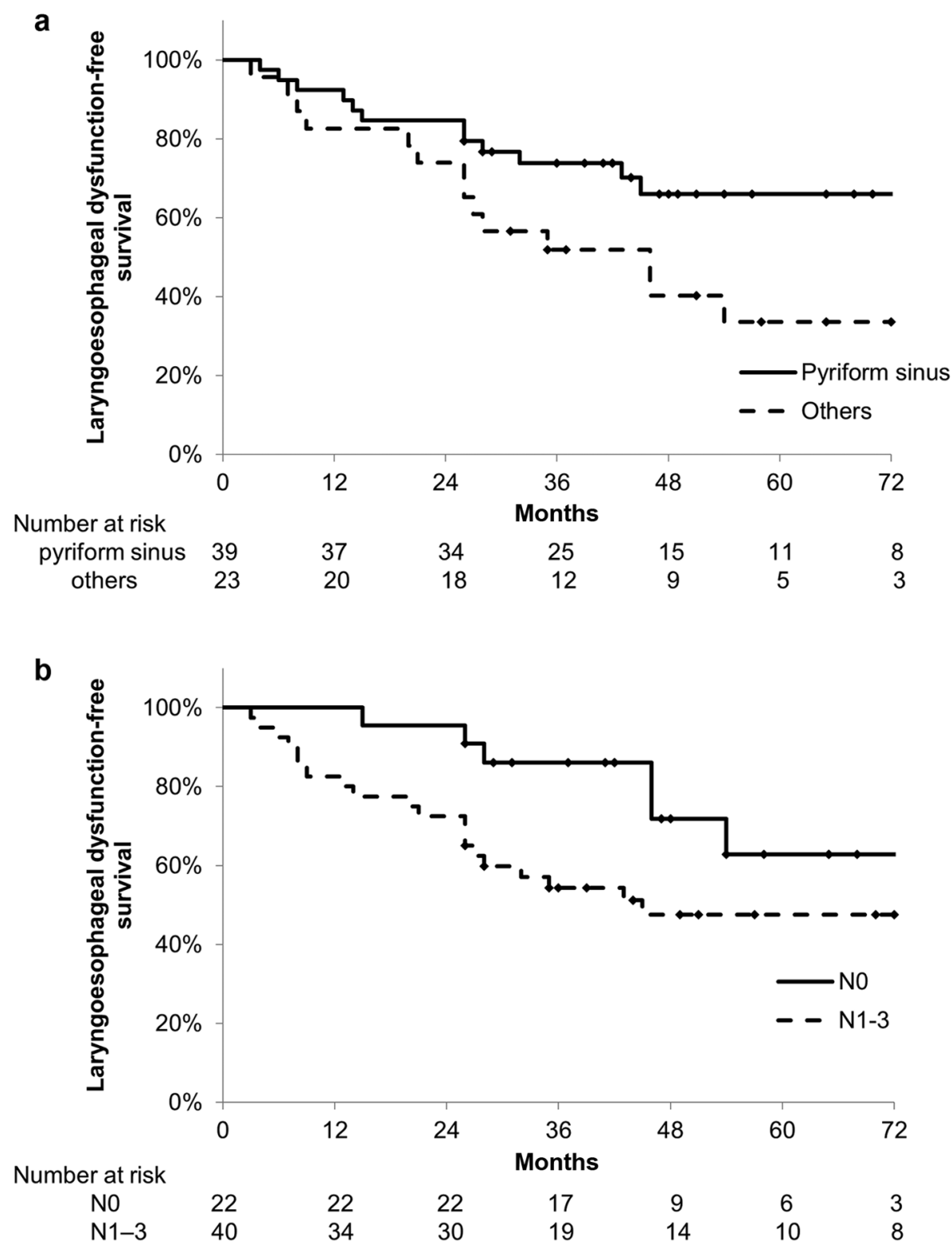

Figure 2. Laryngoesophageal dysfunction-free survival (LEDFS) according to primary tumor location and N category. (a) The 5-year LEDFS rates of patients with tumors located in the pyriform sinus and those with tumors located elsewhere were $66.0 \%$ and $33.6 \%$, respectively. (b) The 5-year LEDFS rates of patients with NO disease and those with N1-3 disease were $62.8 \%$ and $47.5 \%$, respectively.

patients receiving definitive RT depended on a feeding tube at 2 years $(10,11)$. However, it should be noted that these results are based on non-IMRT techniques, and IMRT might lead to a reduction in late toxicities. Most previous IMRT studies have analyzed OPC, HPC, and laryngeal cancer concurrently, and there are few studies that have specifically focused on HPC (7, 12-15). Therefore, the effect of IMRT on late toxicities is unclear in the case with HPC, especially in the Japanese population. In addition, since OPC treatment results differ depending on human papillomavirus status, and the irradiated area is also different between OPC and HPC, we believe that OPC and HPC should be evaluated separately. Hence, the present study reported treatment outcomes after definitive RT using VMAT in patients with HPC, including examination of late toxicities such as laryngeal and pharyngeal dysfunction.

Table IV shows the clinical results after definitive RT using IMRT or non-IMRT techniques for patients with HPC. According to previous studies, the 3- and 5-year OS rates after IMRT for patients with HPC were almost 50-80\% and $35-44 \%$, respectively $(7,12-15)$. In contrast, several studies 
Table II. Acute and late toxicities of included patients.

\begin{tabular}{|c|c|c|c|c|c|c|c|c|}
\hline \multirow[t]{3}{*}{ Toxicity } & \multicolumn{8}{|c|}{ Common Terminology Criteria for Adverse Events Ver 4.0} \\
\hline & \multicolumn{2}{|c|}{ Grade $0-1$} & \multicolumn{2}{|c|}{ Grade 2} & \multicolumn{2}{|c|}{ Grade 3} & \multicolumn{2}{|c|}{ Grade 4} \\
\hline & $\mathrm{N}$ & $100(\%)$ & $\mathrm{N}$ & $100(\%)$ & $\mathrm{N}$ & $100(\%)$ & $\mathrm{N}$ & $100(\%)$ \\
\hline \multicolumn{9}{|l|}{ Acute toxicity } \\
\hline \multicolumn{9}{|l|}{ Non-hematologic toxicity } \\
\hline Dysphagia & 10 & 16.1 & 27 & 43.5 & 25 & 40.3 & 0 & 0 \\
\hline Mucositis & 6 & 9.7 & 27 & 43.5 & 29 & 46.8 & 0 & 0 \\
\hline Dermatitis & 19 & 30.6 & 24 & 38.7 & 19 & 30.6 & 0 & 0 \\
\hline Dysgeusia & 29 & 46.8 & 33 & 53.2 & 0 & 0 & 0 & 0 \\
\hline Xerostomia & 37 & 59.7 & 25 & 40.3 & 0 & 0 & 0 & 0 \\
\hline \multicolumn{9}{|l|}{ Hematologic toxicity } \\
\hline Leukopenia & 20 & 32.3 & 19 & 30.6 & 22 & 35.5 & 1 & 1.6 \\
\hline Neutropenia & 31 & 50.0 & 12 & 19.4 & 18 & 29.0 & 1 & 1.6 \\
\hline Anemia & 27 & 43.5 & 29 & 46.8 & 6 & 9.7 & 0 & 0 \\
\hline \multicolumn{9}{|l|}{ Late toxicity } \\
\hline \multicolumn{9}{|l|}{ Non-hematologic toxicity } \\
\hline Dysphagia & 55 & 88.7 & 3 & 4.8 & 4 & 6.5 & 0 & 0 \\
\hline Dysgeusia & 61 & 98.4 & 1 & 1.6 & 0 & 0 & 0 & 0 \\
\hline Xerostomia & 56 & 90.3 & 6 & 9.7 & 0 & 0 & 0 & 0 \\
\hline Osteonecrosis of jaw & 61 & 98.4 & 1 & 1.6 & 0 & 0 & 0 & 0 \\
\hline
\end{tabular}

Table III. Univariate and multivariate analyses of predictive factors.

\begin{tabular}{|c|c|c|c|c|c|c|c|c|c|c|}
\hline \multirow[b]{2}{*}{$\begin{array}{l}\text { Investigated } \\
\text { factors }\end{array}$} & \multicolumn{5}{|c|}{ Overall survival } & \multicolumn{5}{|c|}{ Laryngoesophageal dysfunction-free survival } \\
\hline & $\begin{array}{c}\text { 3-year } \\
\text { OS } \\
\%\end{array}$ & $\begin{array}{c}5 \text {-year } \\
\text { OS } \\
\%\end{array}$ & $\begin{array}{c}\text { UVA } \\
p \text {-Value }\end{array}$ & $\begin{array}{c}\text { MVA } \\
p \text {-Value }\end{array}$ & $\begin{array}{c}\text { Hazard } \\
\text { ratio } \\
(95 \% \mathrm{CI})\end{array}$ & $\begin{array}{c}\text { 3-year } \\
\text { LEDFS } \\
\%\end{array}$ & $\begin{array}{c}\text { 5-year } \\
\text { LEDFS } \\
\%\end{array}$ & $\begin{array}{c}\text { UVA } \\
p \text {-Value }\end{array}$ & $\begin{array}{c}\text { MVA } \\
p \text {-Value }\end{array}$ & $\begin{array}{l}\text { Hazard } \\
\text { ratio } \\
(95 \% \mathrm{CI})\end{array}$ \\
\hline \multicolumn{11}{|l|}{ Age } \\
\hline $\begin{array}{l}<65 \text { years } \\
\geq 65 \text { years }\end{array}$ & $\begin{array}{l}80.6 \\
73.2\end{array}$ & $\begin{array}{l}68.7 \\
54.4\end{array}$ & 0.3133 & ns & - & $\begin{array}{l}70.2 \\
61.5\end{array}$ & $\begin{array}{l}55.8 \\
50.2\end{array}$ & 0.4429 & ns & - \\
\hline \multicolumn{11}{|l|}{ Gender } \\
\hline $\begin{array}{l}\text { Male } \\
\text { Female }\end{array}$ & $\begin{array}{l}76.3 \\
80.0\end{array}$ & $\begin{array}{l}60.4 \\
60.0\end{array}$ & 0.6487 & 0.2077 & $0.3594(0.0732-1.7655)$ & $\begin{array}{l}65.9 \\
60.0\end{array}$ & $\begin{array}{l}51.7 \\
60.0\end{array}$ & 0.6767 & 0.1707 & $0.3301(0.0676-1.6115)$ \\
\hline \multicolumn{11}{|l|}{ Location $(v s)}$. \\
\hline $\begin{array}{l}\text { Pyriform sinus } \\
\text { Others }\end{array}$ & $\begin{array}{l}81.5 \\
68.0\end{array}$ & $\begin{array}{l}67.1 \\
47.6\end{array}$ & 0.3133 & 0.0817 & $0.4525(0.1853-1.1051)$ & $\begin{array}{l}73.8 \\
51.8\end{array}$ & $\begin{array}{l}66.0 \\
33.6\end{array}$ & 0.0813 & 0.0152 & $0.3738(0.1688-0.8274)$ \\
\hline \multicolumn{11}{|l|}{ Stage } \\
\hline $\begin{array}{l}\text { I-II } \\
\text { III-IV }\end{array}$ & $\begin{array}{l}100 \\
70.7\end{array}$ & $\begin{array}{l}80.0 \\
55.2\end{array}$ & 0.0755 & ns & - & $\begin{array}{l}100 \\
56.9\end{array}$ & $\begin{array}{l}66.7 \\
50.5\end{array}$ & 0.0808 & ns & - \\
\hline \multicolumn{11}{|l|}{$\mathrm{T}$ category } \\
\hline $\begin{array}{l}\text { T1-2 } \\
\text { T3-4 }\end{array}$ & $\begin{array}{l}86.9 \\
70.2\end{array}$ & $\begin{array}{l}62.9 \\
58.7\end{array}$ & 0.3355 & ns & - & $\begin{array}{l}75.0 \\
59.6\end{array}$ & $\begin{array}{l}50.5 \\
55.9\end{array}$ & 0.5526 & ns & - \\
\hline \multicolumn{11}{|l|}{$\mathrm{N}$ category } \\
\hline $\begin{array}{l}\text { N0 } \\
\text { N1-3 }\end{array}$ & $\begin{array}{l}90.7 \\
69.0\end{array}$ & $\begin{array}{l}75.6 \\
52.0\end{array}$ & 0.0481 & 0.0202 & $0.2623(0.0847-0.8118)$ & $\begin{array}{l}86.1 \\
54.4\end{array}$ & $\begin{array}{l}62.8 \\
47.5\end{array}$ & 0.0502 & 0.0146 & $0.3073(0.1192-0.7920)$ \\
\hline \multicolumn{11}{|l|}{ Smoking history } \\
\hline $\begin{array}{l}\text { No } \\
\text { Yes }\end{array}$ & $\begin{array}{c}100 \\
70.9\end{array}$ & $\begin{array}{l}63.6 \\
60.2\end{array}$ & 0.4619 & ns & - & $\begin{array}{l}75.0 \\
63.1\end{array}$ & $\begin{array}{l}50.0 \\
56.1\end{array}$ & 0.8921 & ns & - \\
\hline
\end{tabular}

OS, Overall survival; UVA, univariate analysis; MVA, multivariate analysis; CI, confidence interval; LEDFS, laryngoesophageal dysfunction-free survival; ns, non significant. 
Table IV. Clinical results of definitive radiotherapy for patients with hypopharyngeal cancer.

\begin{tabular}{|c|c|c|c|c|c|c|c|}
\hline & \multirow[t]{3}{*}{$\mathrm{N}$} & \multirow{3}{*}{$\begin{array}{l}\text { Median } \\
\text { follow-up } \\
\text { (month) }\end{array}$} & \multirow{3}{*}{$\begin{array}{c}\text { Stage } \\
\text { (Stage: \%) }\end{array}$} & \multicolumn{4}{|c|}{ Treatment outcome } \\
\hline & & & & \multirow{2}{*}{$\begin{array}{l}\text { OS } \\
(\%)\end{array}$} & \multirow{2}{*}{$\begin{array}{l}\text { LPS } \\
(\%)\end{array}$} & \multicolumn{2}{|c|}{ Late AE (\%) } \\
\hline & & & & & & $\begin{array}{c}\text { Disphagia } \\
\text { ( } \geq \text { Grade } 3 \text { ) }\end{array}$ & $\begin{array}{c}\text { Xerostomia } \\
(\geq \text { Grade } 2)\end{array}$ \\
\hline \multicolumn{8}{|l|}{ IMRT study } \\
\hline Liu et al. (2010) (12) & 27 & 53 & II: 19 III: 15 IV: 67 & $\begin{array}{l}3 y: 52 \\
5 y: 35\end{array}$ & $\begin{array}{l}3 y: 60 \\
5 y: 60\end{array}$ & 4 & 44 \\
\hline Huang et al. (2010) (13) & 33 & 26 & II: 6 III: 15 IV: 79 & $5 y: 44$ & $5 y: 40$ & 3 & 0 \\
\hline Takehana et al. (2016) (7) & 56 & 43 & na & $3 y: 81$ & $3 y: 54$ & na & 10 \\
\hline Kılıç et al. (2018) (15) & 2098 & 44 & I: 3 II: 11 III: 24 IV: 63 & $5 y: 42$ & na & na & na \\
\hline This study (2020) & 62 & 49 & I: 8 II: 11 III: 5 IV: 76 & $\begin{array}{l}3 \mathrm{y}: 77 \\
5 \mathrm{y}: 60\end{array}$ & $\begin{array}{l}3 y: 66^{*} \\
5 y: 53^{*}\end{array}$ & 7 & 10 \\
\hline \multicolumn{8}{|l|}{ Non-IMRT study } \\
\hline Rabbani et al. (2008) (16) & 123 & 128 & I: 5 II: 15 III: 17 IV: 63 & $5 y: 35$ & na & na & na \\
\hline Takehana et al. (2016) (7) & 148 & 43 & na & $3 y: 78$ & $3 y: 71$ & na & na \\
\hline Kilıç et al. (2018) (15) & 1830 & 44 & I: 5 II: 11 III: 22 IV: 62 & $5 y: 37$ & na & na & na \\
\hline Juloori et al. (2018) (17)** & 54 & 50 & III: 22 IV: 78 & $5 y: 62$ & na & 36 & 77 \\
\hline
\end{tabular}

OS, Overall survival; LPS, functional larynx preservation survival; AE, adverse event; IMRT, intensity-modulated radiotherapy; na, not available. *Laryngoesophageal dysfunction-free survival. **This study included almost $10 \%$ patients treated by IMRT.

mentioned treatment results after 3D-CRT for HPC, and the 3- and 5-year OS rates were almost 50-80\% and 35-60\%, respectively $(7,10,11,15-17)$. In the present study, the 3 and 5-year OS rates were $77 \%$ and $60 \%$, respectively. In addition, the 5-year LRC rates of IMRT and non-IMRT studies were reported as $53-78 \%$, and that in our study was $79 \%$. Overall, previous results, including those of our study, are similar between 3D-CRT and IMRT studies.

Regarding late toxicities, grade $\geq 2$ late toxicities were observed in $18 \%$ of patients, grade 2 xerostomia in $10 \%$, and grade 3 dysphagia in $7 \%$ in the present study. In addition, the 3 - and 5-year LEDFS rates were $66 \%$ and 53\%, respectively. These results were also similar to other IMRT studies. In contrast, in a 3D-CRT for HPC study reported by Juloori et al., grade 2 xerostomia was observed in almost $77 \%$ of patients, and grade 3 dysphagia in $36 \%$ (90\% of the total cases received 3D-CRT, and others received IMRT) (17). In addition, in RTOG 91-11, grade 2 xerostomia was observed in almost $50 \%$ of patients, and grade 3 dysphagia in $15 \%$ (4). Therefore, IMRT might reduce adverse events while providing similar disease control in comparison with 3D-CRT, even in patients with HPC.

This study included almost $60 \%$ of total patients receiving induction chemotherapy followed by definitive RT. We considered induction chemotherapy for patients with Stage IV disease. Although induction chemotherapy does not demonstrate a survival benefit compared to CRT alone (4), interest in the utility of induction chemotherapy persists for a few reasons including a reduction in the likelihood of distant metastases, and improvement of local regional control and organ preservation (2). Tumor bulk reduction by induction chemotherapy, as well as radiation dose reduction in VMAT for organs at risk, might have contributed to the low incidence of late toxicities.

The present study also revealed tumor location (pyriform sinus) and $\mathrm{N}$ category (N0 disease) as significant predictive factors of good LEDFS. As there are still few reports that mention LEDFS after definitive RT for HPC, the predictive factor of good LEDFS is unclear. Primary tumor location and $\mathrm{N}$ category are known to be correlated with survival (18), and might be predictive factors of LEDFS.

Our study had certain limitations, including its retrospective and single-institution design. In addition, because most previous studies of 3D-CRT for HPC lacked functional larynxpreservation survival or LEDFS, it was difficult to compare the functional preservation of the larynx and pharynx after 3DCRT and IMRT. These factors might have introduced potential biases, such as under- or overestimation of the advantage of IMRT over 3D-CRT in late adverse events. However, our assessment of VMAT for HPC is valuable because of the paucity of currently available data. Furthermore, although we evaluated only 62 patients, this represents a relatively large amount of VMAT treatments for HPC cases alone. Therefore, despite its limitations, this study provides useful information regarding definitive RT using VMAT with a relatively long follow-up duration in a large sample size.

In summary, this study reported treatment outcomes after definitive RT using VMAT in patients with HPC, including examination of late toxicities such as dysfunction of the larynx 
and pharynx. We conclude that definitive RT using VMAT is an effective treatment for HPC that might reduce long-term adverse events while providing similar disease control in comparison with 3D-CRT, even in patients with HPC.

\section{Conflicts of Interest}

The Authors declare no conflicts of interest regarding this study.

\section{Authors' Contributions}

Katsumaro Kubo and Yuji Murakami contributed equally to this work. Investigation, project administration, writing of original draft: Katsumaro Kubo. Methodology, writing, reviewing and editing: Yuji Murakami. Writing, reviewing and editing: Nobuki Imano, Yuki Takeuchi, Ikuno Nishibuchi, Tomoki Kimura, Daisuke Kawahara, Kentaro Miki, Akito Saito, Takeo Nakashima, Takao Hamoamoto, Tsutomu Ueda, Sachio Takeno, Yasushi Nagata.

\section{References}

1 Paximadis P, Yoo G, Lin HS, Jacobs J, Sukari A, Dyson G, Christensen $\mathrm{M}$ and Kim H: Concurrent chemoradiotherapy improves survival in patients with hypopharyngeal cancer. Int J Radiat Oncol Biol Phys 82(4): 1515-1521, 2012. PMID: 21658855. DOI: 10.1016/j.ijrobp.2011.04.064

2 National Comprehensive Cancer Network Inc NCCN Clinical Practice Guidelines in Oncology. Head and Neck Cancers version 1. 2020. Available at: https://www.nccn.org/professionals/physician_ gls/pdf/head-and-neck.pdf

3 Pracy P, Loughran S, Good J, Parmar S and Goranova R: Hypopharyngeal cancer: United Kingdom National Multidisciplinary Guidelines. J Laryngol Otol 130(S2): S104-S110, 2016. PMID: 27841124. DOI: $10.1017 /$ S0022215116000529

4 Forastiere AA, Zhang Q, Weber RS, Maor MH, Goepfert H, Pajak TF, Morrison W, Glisson B, Trotti A, Ridge JA, Thorstad W, Wagner H, Ensley JF and Cooper JS: Long-term results of RTOG 91-11: a comparison of three nonsurgical treatment strategies to preserve the larynx in patients with locally advanced larynx cancer. J Clin Oncol 31(7): 845-852, 2013. PMID: 23182993. DOI: 10.1200/JCO.2012.43.6097

5 Mohan R, Wu Q, Manning $\mathrm{M}$ and Schmidt-Ullrich R. Radiobiological considerations in the design of fractionation strategies for intensity-modulated radiation therapy of head and neck cancers. Int J Radiat Oncol Biol Phys 46(3): 619-630, 2000. PMID: 10701741. DOI: 10.1016/s0360-3016(99)00438-1

6 Marta GN, Silva V, de Andrade Carvalho H, de Arruda FF, Hanna SA, Gadia R, da Silva JL, Correa SF, Vita Abreu CE and Riera R: Intensity-modulated radiation therapy for head and neck cancer: systematic review and meta-analysis. Radiother Oncol 110(1): 915, 2014. PMID: 24332675. DOI: 10.1016/j.radonc.2013.11.010

7 Takehana K, Kodaira T, Tachibana H, Kimura K, Shimizu A, Makita C, Tomita N, Nishikawa D, Suzuki H, Hirakawa H, Hanai $\mathrm{N}$ and Hasegawa Y: Retrospective analysis of the clinical efficacy of definitive chemoradiotherapy for patients with hypopharyngeal cancer. Jpn J Clin Oncol 46(4): 344-349, 2016. PMID: 26826721. DOI: 10.1093/jjco/hyv216

8 Lefebvre JL and Ang KK: Larynx preservation clinical trial design: key issues and recommendations-a consensus panel summary. Int J Radiat Oncol Biol Phys 73(5): 1293-303, 2009. PMID: 19306746. DOI: 10.1016/j.ijrobp.2008.10.047

9 Caudell JJ, Schaner PE, Meredith RF, Locher JL, Nabell LM, Carroll WR, Magnuson JS, Spencer SA and Bonner JA: Factors associated with long-term dysphagia after definitive radiotherapy for locally advanced head-and-neck cancer. Int J Radiat Oncol Biol Phys 73(2): 410-415, 2009. PMID: 18635320. DOI: 10.1016/j.ijrobp.2008.04.048

10 Mok G, Gauthier I, Jiang H, Huang SH, Chan K, Witterick IJ, O'Sullivan B, Waldron JN, Bayley AJ, Cho BC, Cummings BJ, Dawson LA, Hope AJ, Kim JJ and Ringash J: Outcomes of intensity-modulated radiotherapy versus conventional radiotherapy for hypopharyngeal cancer. Head Neck 37: 655661, 2015. PMID: 24590756. DOI: 10.1002/hed.23649

11 Katsoulakis E, Riaz N, Hu M, Morris L, Sherman E, McBride S and Lee N: Hypopharyngeal squamous cell carcinoma: Threedimensional or Intensity-modulated radiotherapy? A single institution's experience. Laryngoscope 126(3): 620-626, 2016. PMID: 26597398. DOI: 10.1002/lary.25509

12 Liu WS, Hsin CH, Chou YH, Liu JT, Wu MF, Tseng SW, Lee JK, Tseng HC, Wang TH, Su MC and Lee H: Long-term results of intensity-modulated radiotherapy concomitant with chemotherapy for hypopharyngeal carcinoma aimed at laryngeal preservation. BMC Cancer 10: 102, 2010. PMID: 20298550. DOI: $10.1186 / 1471-2407-10-102$

13 Huang WY, Jen YM, Chen CM, Su YF, Lin CS, Lin YS, Chang YN, Chao HL, Lin KT and Chang LP: Intensity modulated radiotherapy with concurrent chemotherapy for larynx preservation of advanced resectable hypopharyngeal cancer. Radiat Oncol 5: 37, 2010. PMID: 20470428. DOI: 10.1186/1748-717X-5-37

14 Edson MA, Garden AS, Takiar V, Glisson BS, Fuller CD, Gunn GB, Beadle BM, Morrison WH, Frank SJ, Shah SJ, Tao R, William WN, Weber RS, Rosenthal DI and Phan J: Outcomes for hypopharyngeal carcinoma treated with organ-preservation therapy. Head Neck 38: E2091-2099, 2016. PMID: 26920665. DOI: $10.1002 /$ hed .24387

15 Kılıç S, Kılıç SS, Hsueh WD, Eloy JA, Baredes S, Woo Park RC and Mahmoud O: Radiotherapy modality as a predictor of survival in hypopharyngeal cancer. Head Neck 40(11): 24412448, 2018. PMID: 30306665. DOI: 10.1002/hed.25360

16 Rabbani A, Amdur RJ, Mancuso AA, Werning JW, Kirwan J, Morris CG and Mendenhall WM: Definitive radiotherapy for T1T2 squamous cell carcinoma of pyriform sinus. Int J Radiat Oncol Biol Phys 72(2): 351-355, 2008. PMID: 18395359. DOI: 10.1016/j.ijrobp.2008.01.003

17 Juloori A, Koyfman SA, Geiger JL, Joshi NP, Woody NM, Burkey BB, Scharpf J, Lamarre EL, Prendes B, Adelstein DJ, Greskovich JF and Keller L: Definitive chemoradiation in locally advanced squamous cell carcinoma of the hypopharynx: longterm outcomes and toxicity. Anticancer Res 38(6): 3543-3549, 2018. PMID: 29848708. DOI: 10.21873/anticanres.12626

18 Wang YL, Feng SH, Zhu J, Zhu GP, Li DS, Wang Y, Zhu YX, Sun GH and Ji QH: Impact of lymph node ratio on the survival of patients with hypopharyngeal squamous cell carcinoma: a population-based analysis. PLoS One 8(2): e56613, 2013. PMID: 23431384. DOI: 10.1371/journal.pone.0056613

Received May 28, 2020

Revised June 16, 2020

Accepted June 17, 2020 